\title{
LATE NESTING RECORD OF COMMON LOON NEAR RIDING MOUNTAIN NATIONAL PARK
}

KEN KINGDON, Box 314, Onanole, MB, R0J 1N0; E-mail: <ken.kingdon@pc.gc.ca>

As part of the Canadian Lake Loon Survey (CLLS), Octopus Lake (50 37 $\mathrm{N} ; 9957 \mathrm{~W})$ has been surveyed for Common Loons since 1999. The lake is located south of Clear Lake, Manitoba, and just south of the boundary of Riding Mountain National Park. The lake is shaped in such a way that a shallow, reed-filled "isthmus" separates the lake into two territories, allowing for two pairs of loons to nest on the lake.

On the first survey of the lake, 13 June 2008 , loons were present in both territories, as in years past. While one pair had already produced two young by 17 June, the second pair did not appear to be nesting, as both adults were observed feeding in the centre of the lake on 18 June, indicating that they were not incubating eggs.

Despite not expecting to see any sign of nesting, the second pair of loons was resurveyed on 22 July. At that time, one of the loons showed unusual behaviour, and although it did not raise an alarm yodel, it "submarined" several times as it was approached, sinking so that only its head was above the water. It also made several soft calls unfamiliar to me. Due to this behaviour, the loon, which was also swimming surprisingly close to the shore, was approached by kayak. Only when I neared the loon was a nest observed, containing a downy chick and one unhatched egg. The chick was black and did not respond negatively to my approach. It was not swimming, but was simply sitting on the nest, indicating that it had hatched within the previous day. ${ }^{4}$

I immediately left the area to avoid disturbing the loons, but returned to the area 30 July and 6 August. On the latter date, I photographed the loon chick with its parents, as well as the

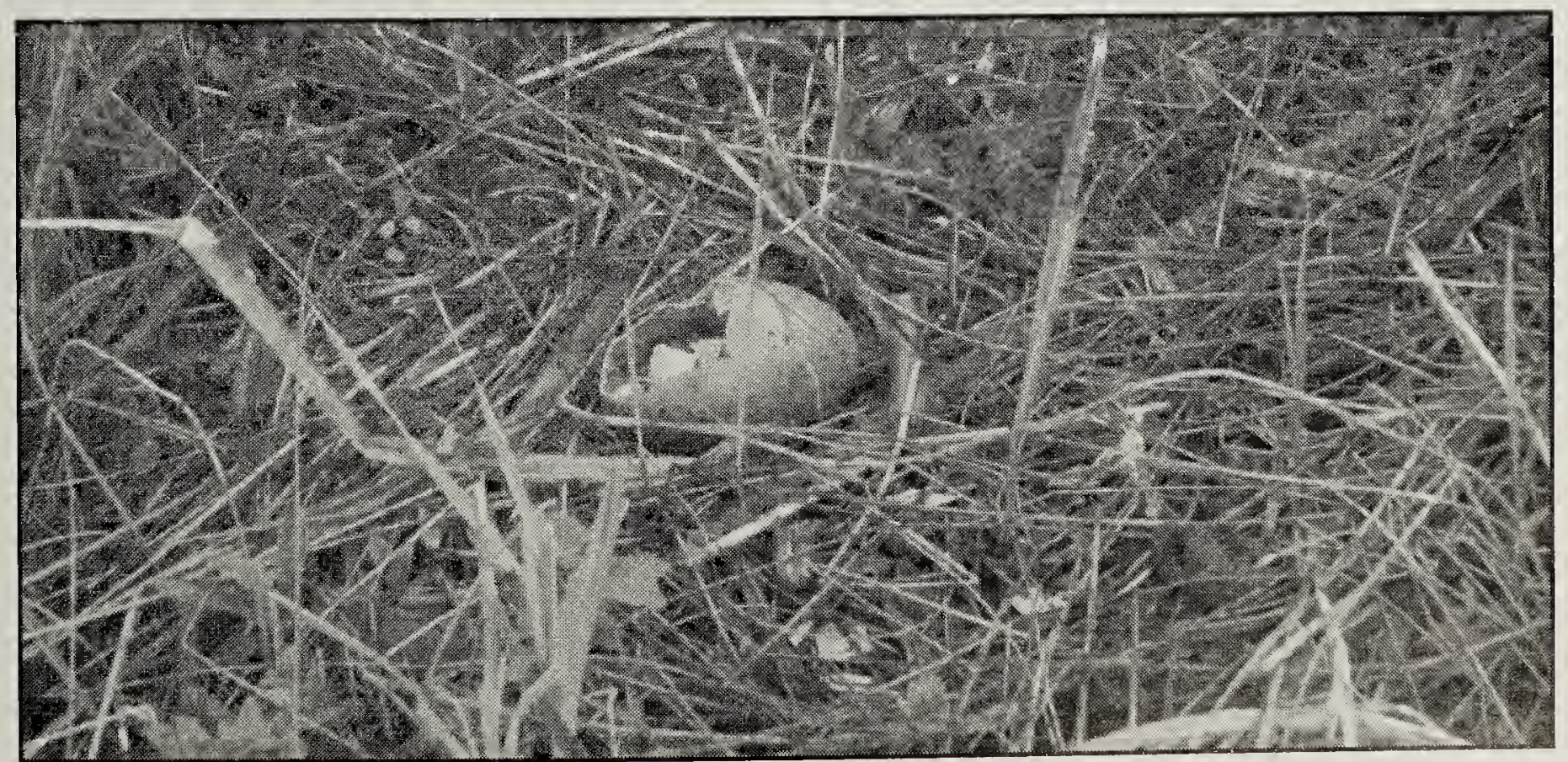

Figure 1. Nest and scavenged egg of late-nesting Common Loon, 6 August 2008.

Ken Kingdon 
nest and the remaining egg (Fig. 1). The egg was partially scavenged, and it appeared that the egg was unfertilized or non-viable, as there was no developed embryo present.

On these visits, the chick was attended by both adults. By 16 August, however, only one adult was present, and there was no time afterwards that more than one adult was seen with the chick. The last date that any adult was seen with the chick was 3 September. The lake was surveyed twice more after 3 September, with the chick being last observed on 6 October. There was no sign of the chick on 18 October, the next date that the lake was surveyed.

These observations fit with late records for nesting by the Common Loon. The latest record for the presence of eggs in Manitoba is 24 July. ${ }^{3}$ There are also at least two records for incubation in North America of 17 July, but while it is unknown whether the Manitoba record resulted in a successful hatch, the Saskatchewan incubation as reported by Yonge was unsuccessful. 1,5 Yonge did record successful hatching into mid-July, in both replacement and original nests, but not beyond 15 July. As for my late nesting record, the eggs were likely laid during the week of 23 June, as the average incubation in Saskatchewan is 28 days, with a range of 27 to 30 days. $^{5}$ Thus, it is unlikely that the loons were incubating eggs at the time of the 18 June survey. In Yonge's study, no clutches were started after 1 July. ${ }^{5}$

It is possible that this chick was the result of a second nesting attempt by the pair - the first nesting attempt may have failed due to high water levels. The weather in the Riding Mountain National Park region during the spring of 2008 was unusual. The early part of spring was marked by relatively dry, cool conditions. Then, starting in midMay, cool and wet weather brought unusual amounts of rain for the region (Stephen Cornelsen, Resource Conservation Department, Riding Mountain National Park, pers. comm.). As a result of the higher than normal precipitation, the water level in Octopus Lake appeared to be at least $15 \mathrm{~cm}$ higher than normal at the time of the first survey date in June. Yonge found that loons will attempt to nest a second time in $45 \%$ of cases where the first clutch is destroyed. ${ }^{5}$

The actual length of time that the chick was tended by an adult is unknown. As stated, the last observation of an adult with the chick was on 3 September, when the chick was 6 weeks old, but the lake was not revisited until 29 September. No adults in Saskatchewan were seen with young after 24 September. ${ }^{5}$

It is unknown whether the loon chick survived. It was last observed on 6 October, at 11 weeks of age. This date is approximately 1 month later than previous observations of loon chicks on Octopus Lake, as most loons depart the lake by early September. By week 11 , loon chicks are generally able to become airborne, but while my observation opportunities were limited, at no time was the chick seen attempting to fly, or even flapping its wings. ${ }^{4}$ As well, the loon chick appeared smaller in size than past fledging chicks observed on the lake.

However, also at 11 weeks of age, chicks are 90 to $100 \%$ independent for feeding, and adult loons will generally leave their young after 10 to 15 weeks of age. ${ }^{4}$ Thus, the chick was likely able to feed itself at that time. Yonge also noted that while chick mortality can be high when first hatched, after 4 weeks of age, no mortality was evident, 
suggesting that the chance of survival was high.

One concern for the chick was freezeup, which could have prevented the chick from feeding and/or getting airborne. However, the autumn weather was considered to be above normal for the month of September, and while there was some localized frost, temperatures generally remained above normal until after Thanksgiving (Environment Canada, 2008). ${ }^{2}$ Thus, weather should not have been a factor in chick survival.

\section{Acknowledgements}

Thank you to Bill Walley, Kurt Mazur, and an anonymous reviewer for their comments on the manuscript.
1. CAMPBELL, R. W. N. K. DAME, I. MCTAGGARTCOWAN, J. M. COOPER, G. W. KAISER, and M. C. E. MCNALL. 1990. The Birds of British Columbia, Vol. I. Introduction and Loons Through Waterfowl. Royal British Columbia Museum, Victoria, BC.

2. ENVIRONMENT CANADA. 2008. Wasagaming Weather Station. Accessed Online: http:// www. weatheroffice.gc.ca/city/pages/mb31 metric e.html

3. MANITOBA AVIAN RESEARCH COMMITTEE. 2003. The Birds of Manitoba. Manitoba Naturalists Society. Winnipeg, MB.

4. MCINTYRE, J.W., and J. F. BARR. 1997. Common Loon (Gavia immer). The Birds of North America Online (A. Poole, Ed.). Ithaca: Cornell Lab of Ornithology; Retrieved from the Birds of North America Online: http://bna.birds.cornell.edu/bna/ species/313

5. YONGE, K. 1981. The Breeding Cycle and Annual Production of the Common Loon (Gavia immer) in the Boreal Forest Region. M.Sc. Thesis, University of Manitoba, Winnipeg, MB.

\section{PUBLICATION AVAILABILITY NOTICE}

TURKEY VULTURES: APHOTOGRAPHIC GUIDE FORAGING NESTLINGS. R.W. Nelson, D. Moore, F. Kunnas, and R. Morse. 2009. Fish and Wildlife Division, Alberta Species at Risk Report No. 124. Edmonton, AB. 44 pp. Descriptions and $80+$ color photos of known-age nestlings, "... are intended to allow users ... to estimate the age of nestling Turkey Vultures, from their own photographs, to within +- two days, without handling the young birds." Part of an ongoing study at the northern edge of the breeding range. Available as a pdf download at: <http://srd.alberta.ca/fishwildlife/speciesatrisk/ projectreports.aspx>

-submitted by Wayne Nelson, <wanelson@telus.net>

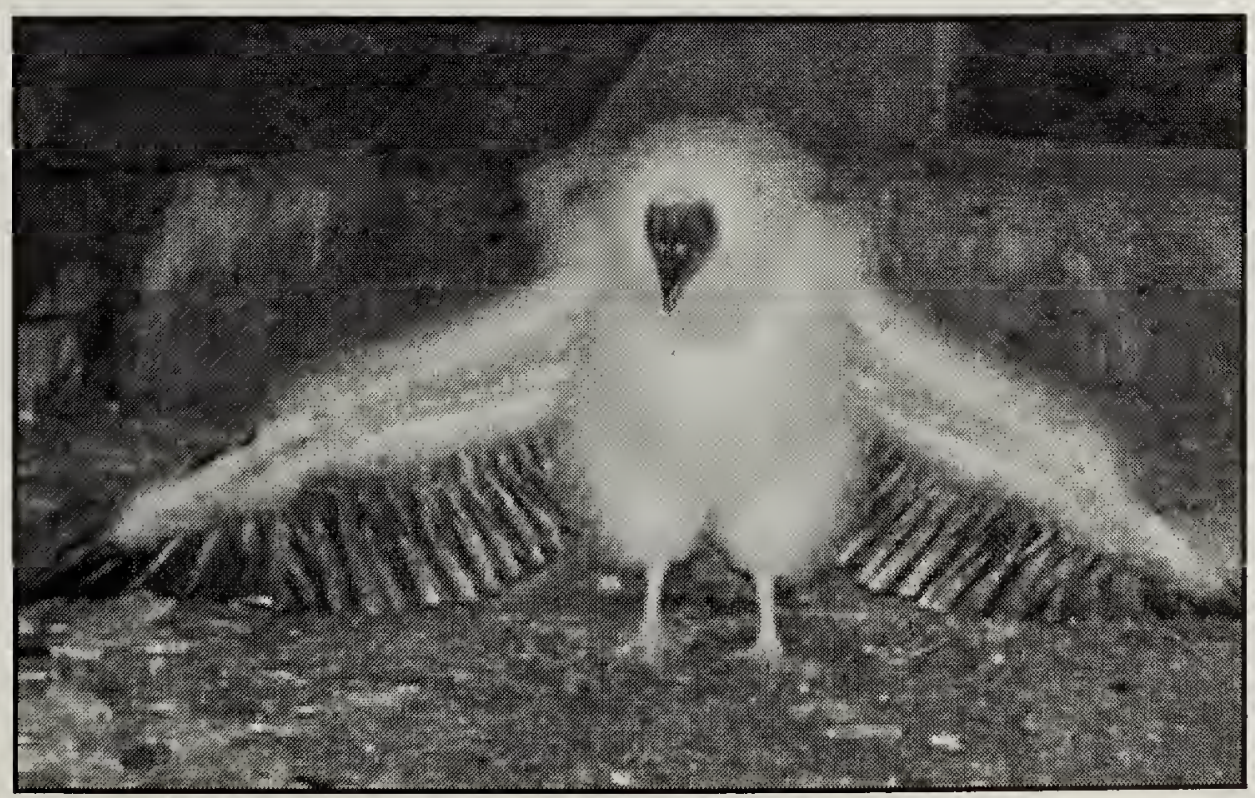

Photo from "TURKEY VULTURES: A PHOTOGRAPHIC GUIDE FOR AGING NESTLINGS" of a 42day-old nestling Turkey Vulture, taken southeast of Elk Pt., $A B$, on 20 July 2008.

Wayne Nelson 